\title{
Micropropagação de Croton antisyphiliticus Mart.
}

\author{
Micropropagation of Croton antisyphiliticus Mart.
}

\section{Taíce Gonçalves de Oliveira ${ }^{\mathrm{I}, \mathrm{II}}{ }^{*}$ Paulo Sérgio Souza Pina ${ }^{\mathrm{II}}$ Bianca Waléria Bertoni ${ }^{\mathrm{III}}$ Suzelei de Castro França ${ }^{\text {III }}$ Ana Maria Soares Pereira ${ }^{\mathrm{I}}$,II}

\section{RESUMO}

\begin{abstract}
Croton antisyphiliticus Mart. ex M. Arg., conhecido popularmente como pé-de-perdiz, é uma planta medicinal nativa do Cerrado, cuja raiz é utilizada na forma de decoctos para combater infecções do aparelho reprodutor masculino $e$ feminino. A coleta da planta é realizada de forma extrativista e não há trabalhos a respeito da sua conservação. $O$ objeto do trabalho foi estabelecer um protocolo de micropropagação de Croton antisyphiliticus. Foram avaliados o efeito de diferentes concentrações das citocininas, o tamanho do recipiente para o cultivo in vitro, o co-cultivo e a posição da gema em relação ao desenvolvimento dos explantes, bem como a influência do AIB no enraizamento in vitro e a aclimatização dos explantes. $O$ melhor desenvolvimento in vitro foi obtido com explantes do tipo gema apical, co-cultivadas em meio MS suplementado com BAP $(1 \mu M)$, em frasco tipo pote. O enraizamento foi obtido em meio MS sem regulador vegetal e a aclimatização pode ser realizada em solo do cerrado com brotações sem a presença de raízes desenvolvidas in vitro.
\end{abstract}

Palavras-chave: cerrado, planta medicinal, pé-de-perdiz, Euphorbiaceae.

\section{ABSTRACT}

Croton antisyphiliticus Mart. ex M. Arg., popularly known as "pé-de-perdiz", is a native medicinal plant of Cerrado, whose root is used in the form of decoctions against infections of the male and female reproductive. The collection of the plant is carried through of extractives form and there are no studies regarding its conservation. The aim of this study was to establish a micropropagation protocol of $\boldsymbol{C}$. antisyphiliticus. The effect of different concentrations of cytokinins, the size of the container for the in vitro culture, co-cultivation and bud position in relation to the development of the explants, as well as the influence of AIB on in vitro rooting and acclimatization of explants were evaluated. The best development in vitro was obtained with apical explants co-cultivated on MS medium supplemented with BAP $(1 \mu \mathrm{M})$ in bottle type pot. Rooting was achieved on MS medium without growth regulators and acclimatization can be performed in Cerrado soil without the presence of shoots developed roots in vitro.

Key words: cerrado, medicinal plant, pé-de-perdiz, Euphorbiaceae.

\section{INTRODUÇÃO}

Um dos principais problemas encontrados em plantas da família Euphorbiaceae é a propagação por semente, muitas das quais apresentam dificuldades no processo inicial de germinação, ou seja, dormência, causada por impedimentos mecânico, químico, térmico e/ou fisiológico (AÑEZ et al., 2005; MENDES et al., 2009). Alternativas como a propagação por estaca tem sido avaliadas para espécies dessa família como, por exemplo, demonstram os trabalhos realizados com Croton cajucara (CONCEIÇÃO et al., 2004) e Sapium glandulatum (FERREIRA et al., 2010).

Croton antisyphiliticus é um subarbusto conhecido como pé-de-perdiz e alcanforeira (SAINTHILARIE, 2009). Segundo dados etnofarmacológicos, o extrato hidroalcoólico das raízes é utilizado no

'Departamento de Horticultura, Faculdade de Ciências Agronômicas, Universidade Estadual Paulista (UNESP), Botucatu, SP, Brasil. IIDepartamento de Odontologia, Universidade Federal de Alfenas ( UNIFAL), Alfenas, MG, Brasil.

"IIDepartamento de Biotecnologia de Plantas Medicinais, Universidade de Ribeirão Preto (UNAERP), 14096-900, Ribeirão Preto, SP, Brasil. E-mail: taice_oliveira@yahoo.com.br. *Autor para correspondência. 
tratamento de algumas doenças sexualmente transmissíveis e de infecções do sistema reprodutor feminino e masculino (BARROS, 1982).

Embora a espécie seja amplamente utilizada por populações que habitam o bioma Cerrado, até o presente momento, não há estudos agronômicos que viabilizem a sua propagação, sendo a exploração realizada exclusivamente por meio de coleta extrativista, o que tem comprometido a sobrevivência das populações naturais, aumentando o risco de extinção e/ou erosão genética da espécie.

Desse modo, o objeto do trabalho foi estabelecer um protocolo de micropropagação de Croton antisyphiliticus.

\section{MATERIAL E MÉTODOS}

Condições gerais dos experimentos

Os experimentos foram conduzidos no Departamento de Biotecnologia de Plantas Medicinais da Universidade de Ribeirão Preto, SP. O meio de cultura utilizado em todos os experimentos foi o MS (MURASHIGE \& SKOOG, 1962), acrescido de 20g L $\mathrm{L}^{-1}$ de sacarose, $2 \mathrm{~g} \mathrm{~L}^{-1}$ de Phytagel $^{\circledR}$ e $\mathrm{pH}$ ajustado para 6,0 . antes da autoclavagem. Todos os cultivos foram mantidos em sala de crescimento com a temperatura de $25 \pm 2^{\circ} \mathrm{C}$ e fotoperíodo de $16 \mathrm{~h}$. A intensidade luminosa foi de aproximadamente $25 \mu \mathrm{M} \mathrm{m}^{-2} \mathrm{~s}^{-1}$, obtida por lâmpadas brancas fluorescentes. Os explantes utilizados nos experimentos de multiplicação, enraizamento in vitro e aclimatização foram oriundos de plantas obtidas de sementes germinadas in vitro, as quais foram submetidas a repicagens e subrepicagens mensalmente por um ano.

Com exceção dos experimentos de cocultivo e tipo de recipiente, os demais experimentos foram realizados em cubetas de vidro com $10 \mathrm{~cm}$ de altura e $2 \mathrm{~cm}$ de diâmetro. Todos os frascos foram vedados com tampa plástica. Os resultados foram submetidos à análise de variância, sendo as médias comparadas pelo teste de Scott Knott a 5\% de probabilidade com o auxílio do programa SISVAR (FERREIRA, 2005).

\section{Germinação in vitro}

Sementes de Croton antisyphiliticus foram coletadas em áreas de fragmento de Cerrado no município de Araxá, MG em fevereiro de 2008. A exsicata foi depositada no Herbário de Plantas Medicinais da UNAERP e recebeu o voucher HPMU 1417.

Logo após a coleta, iniciou-se a assepsia das sementes com a imersão em solução de Cercobin ${ }^{\circledast}$ $1 \%(\mathrm{p} / \mathrm{v})$ por $1 \mathrm{~h}$, sob agitação. Posteriormente, foram imersas em solução de álcool 70\% (v/v) por 1min e em seguida em solução de hipoclorito de cálcio $0,5 \%$ (p/v) por 30min, também sob agitação. Após a assepsia superficial, as sementes foram lavadas com água destilada estéril e inoculadas em cubetas de vidro contendo $5 \mathrm{~mL}$ meio de cultura MS basal e mantidas em sala de crescimento. Foram inoculadas 1.800 sementes distribuídas em 60 repetições de trinta cubetas. As sementes foram avaliadas a cada três dias, por seis meses, quanto à porcentagem de germinação.

\section{Multiplicação in vitro}

Utilizaram-se explantes de plantas germinadas in vitro com aproximadamente $0,5 \mathrm{~cm}$ de comprimento contendo uma gema. Posteriormente, foram avaliados os parâmetros: número de brotos e de gemas, a altura da brotação $(\mathrm{cm})$ e a porcentagem de calos. O delineamento experimental foi inteiramente casualizado e foram utilizadas seis repetições compostas de cinco explantes.

Suplementação com citocininas - Explantes foram inoculados em meio de cultura MS, acrescidos ou não dos seguintes reguladores vegetais: BAP (6benzilaminopurina), cinetina, zeatina e 2 ip (2isopenteniladenina) nas concentrações de $0,50,1,00$, e $2,00 \mu \mathrm{M}$. As avaliações foram realizadas após 30 dias. Produção de múltiplas brotações - Explantes foram inoculados em meio de cultura MS suplementado com $1,0 \mu \mathrm{M}$ de BAP associado ou não com AIA (ácido indolacético) em diferentes concentrações $(0,01,0,10 \mathrm{e}$ $1,00 \mu \mathrm{M})$. As avaliações foram realizadas após 30 dias. Co-cultivo - Nesse experimento, foram inoculados 1 ou 5 explantes por frasco tipo pote $(8 \mathrm{~cm}$ de altura e $5 \mathrm{~cm}$ de diâmetro), contendo meio de cultura MS suplementado com 1,0 $\mu \mathrm{M}$ de BAP. As avaliações foram realizadas após 60 dias.

Tipo de recipiente - Foram utilizados dois tipos de frasco de vidro: cubeta medindo $10 \mathrm{~cm}$ de altura e $2 \mathrm{~cm}$ de diâmetro com capacidade para $34 \mathrm{~mL}$ e pote medindo $8 \mathrm{~cm}$ de altura e $5 \mathrm{~cm}$ de diâmetro com capacidade para $160 \mathrm{~mL}$. Os explantes foram inoculados em meio de cultura MS suplementado com 1,0 $\mu \mathrm{M}$ de BAP e avaliados após 60 dias.

Posição da gema - Foram utilizadas neste experimento a gema axilar localizada na parte basal da brotação e a gema apical. Ambas foram inoculadas em meio MS suplementado com $1,00 \mu \mathrm{M}$ de BAP e avaliadas após 60 dias.

\section{Enraizamento in vitro}

Brotações, com aproximadamente $1,0 \mathrm{~cm}$ contendo gema apical e axilar, foram inoculadas em meio MS acrescido ou não da auxina AIB (ácido 
indolbutírico) nas concentrações 1,00, 2,00, 4,00 e $6,00 \mu \mathrm{M}$, por tempo de exposição alternado de 5, 10, 15 e 30 dias. Após esse período, foram transferidos para o meio basal sem adição de regulador vegetal. $O$ delineamento experimental foi inteiramente casualizado e foram utilizadas três repetições compostas de cinco explantes, sendo avaliadas, aos 30 dias de cultivo, as porcentagens de enraizamento e formação de calo, o número e o comprimento $(\mathrm{cm})$ das raízes.

\section{Aclimatização}

Brotações com 2,5cm de altura, sem raízes, multiplicadas in vitro, foram lavadas em água corrente até a retirada total de resíduos de $\mathrm{Phytagel}^{\circledR}$ e posteriormente plantadas em vaso contendo solo ou substrato Plantmax ${ }^{\circledR}$, ambos autoclavados por duas horas. Os vasos foram cobertos com saco de polietileno transparente e o fornecimento de água foi diário $(10 \mathrm{~mL})$, vertido em recipiente raso alocado embaixo do vaso (Figura 1B). Os vasos foram mantidos em condições controladas de temperatura $\left(25 \pm 2^{\circ} \mathrm{C}\right)$ e umidade $(70 \%)$. Uma semana após as transferências das brotações para condição ex vitro, os sacos plásticos foram perfurados utilizando palitos de madeira $(2,2 \mathrm{~mm})$ e, aos cinquenta dias, os sacos foram removidos totalmente. O delineamento experimental foi inteiramente casualizado, foram utilizados três repetições compostas de 10 explantes por tratamento e realizadas observações diárias quanto à sobrevivência das plântulas. Nesse experimento, foi avaliado o índice de sobrevivência das plantas.

\section{RESULTADOS E DISCUSSÃO}

\section{Germinação in vitro}

A assepsia utilizada foi eficiente, pois apenas $20 \%$ das sementes contaminaram, ou seja, das 1800 sementes, 360 sofreram contaminação, sendo que, das últimas, $6 \%( \pm 1,2)$ foram contaminadas por fungos, $10 \%$ $( \pm 4,72)$ por bactéria e $4 \%( \pm 0,8)$ por contaminação mista. A porcentagem de germinação das sementes inoculadas in vitro foi muito baixa, na ordem de $0,4 \% \pm 0,08$ ( 7 sementes), elas começaram a germinar a partir de 45 dias e não germinaram mais após seis meses.

A reduzida porcentagem de germinação de sementes de $\boldsymbol{C}$. antisyphiliticus mostra que elas apresentam dormência, considerando que toda semente que não germina no período de quatro semanas são enquadradas nessa categoria (BASKIN \& BASKIN, 1998). Este fato evidencia a necessidade de realizar estudos futuros mais específicos que visem a encontrar condições ideais de germinação destas sementes e, ao mesmo tempo, mostra a importância de se estabelecer protocolo de micropropagação como alternativa viável de se propagar esta espécie em larga escala.

\section{Multiplicação in vitro}

Suplementação com citocininas - As citocininas BAP $(1,0$ e $2,0 \mu \mathrm{M})$ e cinetina $(0,5$ e $1,0 \mu \mathrm{M})$ apresentaram os melhores resultados quanto ao número de brotações 1,72 e 1,97 e 2,00 e 1,81, respectivamente (Tabela 1). Quanto à altura das brotações, os melhores resultados foram obtidos com Zeatina na concentração de $2,0 \mu \mathrm{M}$ $(1,49)$ e com $0,5 \mu \mathrm{M}(1,25)$ de BAP. As citocininas 2ip, BAP e zeatina na concentração de $1,0 \mu \mathrm{M}$ apresentaram em média três gemas por explante. Quanto à presença de calos na base dos explantes, as citocininas zeatina $(0,5$ e $1,0 \mu \mathrm{M})$ e 2 ip $(1,0$ e $2,0 \mu \mathrm{M})$ foram as que promoveram as menores porcentagem de calos $17 \% \mathrm{e}$ $27 \%$ e $20 \%$ e $27 \%$, respectivamente. Porém, foi observado, durante o estudo, que a formação de calos na base dos propágulos de $\boldsymbol{C}$. antisyphiliticus não interferiu no desenvolvimento dos mesmos.

A citocinina BAP na concentração de $1,0 \mu \mathrm{M}$ apresentou a maior taxa de multiplicação $(5,03)$, quando

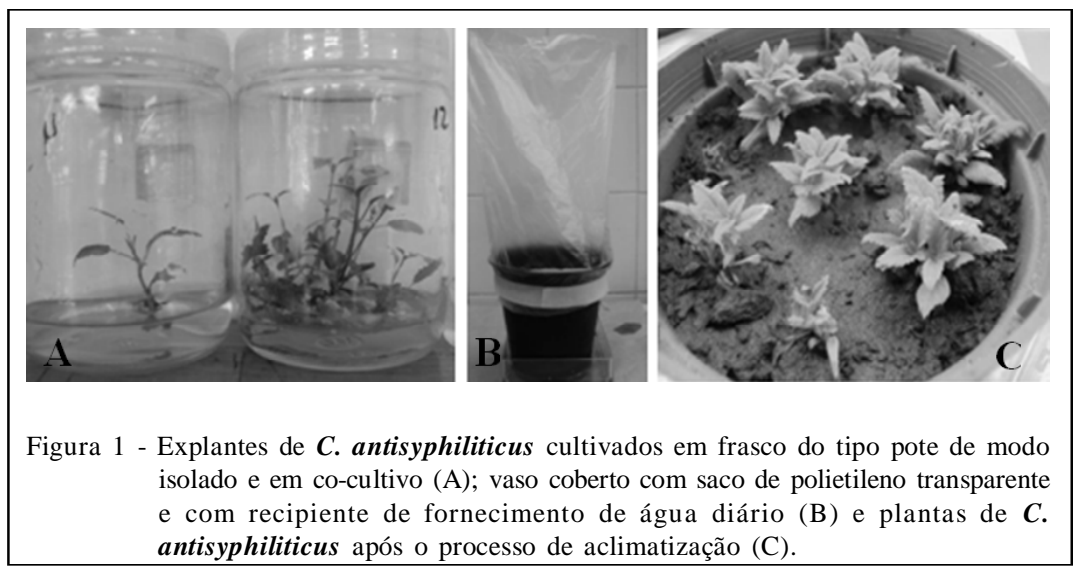

Ciência Rural, v.41, n.10, out, 2011. 
Tabela 1 - Efeito da adição das citocininas, BAP, 2ip, cinetina e zeatina em diferentes concentrações na porcentagem de calos, no número de gemas e brotos, na altura da brotação e na taxa de multiplicação aos 30 dias, UNAERP, Ribeirão Preto, SP, 2010.

\begin{tabular}{|c|c|c|c|c|c|}
\hline \multirow{2}{*}{ ParâmetrosAnalisados } & \multirow{2}{*}{$\begin{array}{c}\text { Concentração } \\
\mu \mathrm{M}\end{array}$} & \multicolumn{4}{|c|}{ - } \\
\hline & & 2ip & BAP & CINETINA & ZEATINA \\
\hline \multirow{4}{*}{$\mathrm{n}^{\mathrm{o}}$ brotos } & 0,0 & $1,17 \mathrm{aA}$ & $1,17 \mathrm{bA}$ & $1,17 \mathrm{bA}$ & $1,17 \mathrm{aA}$ \\
\hline & 0,50 & $1,46 \mathrm{aA}$ & $1,25 \mathrm{bA}$ & $1,93 \mathrm{aA}$ & $1,42 \mathrm{aA}$ \\
\hline & 1,00 & $1,05 \mathrm{aB}$ & $1,72 \mathrm{aA}$ & $1,81 \mathrm{aA}$ & $1,24 \mathrm{aB}$ \\
\hline & 2,00 & $1,05 \mathrm{aB}$ & $1,97 \mathrm{aA}$ & $1,45 \mathrm{bB}$ & $1,12 \mathrm{aB}$ \\
\hline \multirow{4}{*}{ altura brotação $(\mathrm{cm})$} & 0,0 & $0,45 \mathrm{aA}$ & $0,45 \mathrm{bA}$ & $0,45 \mathrm{aA}$ & $0,45 \mathrm{cA}$ \\
\hline & 0,50 & $0,89 \mathrm{aA}$ & $1,25 \mathrm{aA}$ & $0,63 \mathrm{aA}$ & $0,70 \mathrm{cA}$ \\
\hline & 1,00 & $0,67 \mathrm{aA}$ & $0,79 \mathrm{bA}$ & $0,44 \mathrm{aA}$ & $1,00 \mathrm{bA}$ \\
\hline & 2,00 & $0,59 \mathrm{aB}$ & $0,43 \mathrm{bB}$ & $0,31 \mathrm{aB}$ & $1,49 \mathrm{aA}$ \\
\hline \multirow{4}{*}{$\mathrm{n}^{\mathrm{o}}$ gemas } & 0,0 & $1,59 \mathrm{bA}$ & $1,59 \mathrm{bA}$ & $1,59 \mathrm{aA}$ & $1,59 \mathrm{bA}$ \\
\hline & 0,50 & $2,04 \mathrm{bA}$ & $3,00 \mathrm{aA}$ & $1,57 \mathrm{aA}$ & $2,26 \mathrm{bA}$ \\
\hline & 1,00 & $2,98 \mathrm{aA}$ & $2,90 \mathrm{aA}$ & $1,89 \mathrm{aA}$ & $3,02 \mathrm{aA}$ \\
\hline & 2,00 & $2,57 \mathrm{aB}$ & $1,62 \mathrm{bB}$ & $1,63 \mathrm{aB}$ & $3,85 \mathrm{aA}$ \\
\hline \multirow{4}{*}{$\%$ calos } & 0,0 & $57 \mathrm{bA}$ & $57 \mathrm{aA}$ & $57 \mathrm{aA}$ & $57 \mathrm{bA}$ \\
\hline & 0,50 & $40 \mathrm{bA}$ & $47 \mathrm{aA}$ & $43 \mathrm{aA}$ & $17 \mathrm{aA}$ \\
\hline & 1,00 & $20 \mathrm{aB}$ & $73 \mathrm{aA}$ & $43 \mathrm{aB}$ & $27 \mathrm{aB}$ \\
\hline & 2,00 & $27 \mathrm{aB}$ & $80 \mathrm{aA}$ & $47 \mathrm{aB}$ & $43 \mathrm{bB}$ \\
\hline \multirow{4}{*}{$\begin{array}{l}\text { Taxa de multiplicação } \\
\text { (n⿳丷ㅁ broto } x \mathrm{n}^{\circ} \text { gema) }\end{array}$} & 0,0 & $1,88 \mathrm{a}$ & $1,88 \mathrm{~b}$ & $1,88 \mathrm{a}$ & $1,88 \mathrm{a}$ \\
\hline & 0,50 & $2,77 \mathrm{a}$ & $3,69 b$ & $3,49 \mathrm{a}$ & $3,23 \mathrm{a}$ \\
\hline & 1,00 & $3,11 \mathrm{~b}$ & $5,03 \mathrm{a}$ & $3,15 b$ & $3,70 \mathrm{~b}$ \\
\hline & 2,00 & $2,73 b$ & $3,14 \mathrm{~b}$ & $2,31 b$ & $4,29 \mathrm{a}$ \\
\hline
\end{tabular}

Médias seguidas da mesma letra minúscula na coluna e maiúscula na linha não diferem entre si a 5\% de probabilidade pelo teste Scott Knott.

comparada com os outros reguladores avaliados (Tabela 1). Segundo Santos et al. (2006), a taxa de multiplicação (no broto x no gema) é um parâmetro importante, porque possibilita verificar a velocidade do processo de micropropagação. Assim, a citocinina BAP $(1,0 \mu \mathrm{M})$ é o regulador vegetal mais indicado para promover a multiplicação de explantes de $\boldsymbol{C}$. antisyphiliticus.

Produção de múltiplas brotações - A associação de AIA com BAP não promoveu múltiplas brotações, ao contrário, os explantes mantidos em meio de cultura contendo esses reguladores apresentaram reduzido desenvolvimento. Além disso, houve intensa proliferação dos calos na parte aérea, que foi proporcional ao aumento da concentração de AIA utilizada. De certa forma, esse resultado já era esperado, pois a ação de AIA sobre a proliferação celular é uma das respostas mais previsíveis em experimentos com cultura de tecido. Estudos realizados in vitro com as espécies Myracrodruon urundeuva e Tainia latifolia mostraram resultados semelhantes aos encontrados com $\boldsymbol{C}$. antisyphiliticus (ANDRADE et al., 2000; SUNGKUMLONG \& DEB, 2009).
Co-cultivo - Com relação ao número de gemas de $\boldsymbol{C}$. antisyphiliticus, o cultivo de um explante por frasco apresentou valor superior $(4,80)$ em relação ao cocultivo com cinco explantes por frasco $(3,22)$; quanto à porcentagem de sobrevivência dos explantes, número e altura de brotos e porcentagem de calos não houve diferença estatística entre os tratamentos. Entretanto, as brotações que foram co-cultivadas mostraram-se mais robustas (Figura 1A) o que corrobora com o trabalho realizado com Croton sublyratus, no qual todo o protocolo de micropropagação foi desenvolvido com sucesso a partir da condição de co-cultivo (SHIBATA et al., 1996) e também com os dados obtidos por PEREIRA et al. (1999) com as espécies Cephaelis ipecacuanha e Eclipta alba, que se mostraram mais vigorosas ao serem co-cultivadas.

O co-cultivo in vitro é uma estratégia importante quanto ao protocolo de micropropagação, pois viabiliza a multiplicação em nível de biofábrica em função da redução de custos com meios de cultura e com regulador vegetal, além de acelerar o processo de repicagem.

Ciência Rural, v.41, n.10, out, 2011. 
Tipo de recipiente - $\mathrm{O}$ frasco tipo pote apresentou os melhores resultados quanto ao número de gemas $(4,80)$ e altura das brotações $(1,51 \mathrm{~cm})$ quando comparado ao frasco tipo cubeta (1,60 e 0,46, respectivamente). Em relação ao número de brotos, porcentagem de calos e de sobrevivência, não houve diferença significativa entre os tipos de frascos avaliados. Embora estatisticamente não tenha sido observada diferença entre os tratamentos, os propágulos desenvolvidos em frasco tipo pote apresentaram valores superiores àqueles crescidos em cubetas, além de que se mostraram mais robustos. Esses dados corroboram com o estudo realizado com Pfaffia glomerata, que mostra ser o recipiente grande o mais adequado para o crescimento em biomassa das brotações in vitro (NICOLOSO \& ERIG, 2002).

O sucesso do cultivo em recipiente do tipo pote pode estar relacionado a uma maior disponibilidade de gases no interior do frasco, o que propicia a intensificação das reações de fotossíntese, permitindo assim maior desenvolvimento das plantas cultivadas nesses recipientes.

Posição da gema - A gema apical apresentou melhores resultados quanto à porcentagem de sobrevivência $(100 \%)$, número de gemas $(2,23)$, altura da brotação $(0,72 \mathrm{~cm})$ e taxa de multiplicação $(2,70)$, diferindo significativamente da gema basal $(76,67 \%, 1,27,0,31 \mathrm{~cm}$ e 1,69 , respectivamente). Resultado semelhante foi obtido com Macrosyphonia velame, outra espécie nativa do Cerrado, cuja gema apical mostrou os melhores resultados, possibilitando a obtenção de um maior índice de multiplicação in vitro da espécie (MARTINS et al., 2011).

\section{Enraizamento in vitro}

O meio MS basal sem regulador vegetal produziu a maior porcentagem de enraizamento (80\%) e a exposição das brotações de $\boldsymbol{C}$. antisyphiliticus a $1 \mu \mathrm{M}$ de $\mathrm{AIB}$, por dez dias, promoveu maior número de raízes $(1,75)$ (Tabela 2). Entretanto, as brotações de $\boldsymbol{C}$. antisyphiliticus, expostas a diferentes concentrações de AIB, mostraram-se amareladas com intensa formação de calos e aspectos de senescência. Essa resposta mostra que houve em todas as concentrações utilizadas algum nível de toxicidade, o que pode estar relacionado à presença de elevada concentração de auxina endógena nos tecidos das brotações.

Embora tenha sido obtido enraizamento das brotações de $\boldsymbol{C}$. antisyphiliticus, o desenvolvimento das raízes não foi expressivo, sendo $0,30 \mathrm{~cm}$ o maior tamanho observado. Resultado semelhante foi relatado

Tabela 2 - Efeito da adição de AIB na porcentagem de enraizamento, número e tamanho das raízes, UNAERP, Ribeirão Preto, SP, 2011.

\begin{tabular}{|c|c|c|c|c|c|c|}
\hline & & & & 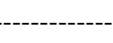 & . & \\
\hline \multirow{7}{*}{ 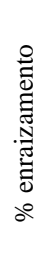 } & Concentração & 5 & 10 & 15 & 30 & $\mathrm{CV} \%$ \\
\hline & $0 \mu \mathrm{M}$ AIB & $80,00 \mathrm{aA}$ & $80,00 \mathrm{aA}$ & $80,00 \mathrm{aA}$ & $80,00 \mathrm{aA}$ & 0,00 \\
\hline & $1 \mu \mathrm{M}$ AIB & $53,00 \mathrm{bA}$ & $66,67 \mathrm{bA}$ & $40,00 \mathrm{bA}$ & $40,00 \mathrm{bA}$ & 22,17 \\
\hline & $2 \mu \mathrm{M}$ AIB & $33,33 \mathrm{cB}$ & $6,67 \mathrm{eC}$ & $33,33 \mathrm{bB}$ & $46,67 \mathrm{bA}$ & 16,69 \\
\hline & $4 \mu \mathrm{M}$ AIB & $10,00 \mathrm{dD}$ & $40,00 \mathrm{cA}$ & $33,33 \mathrm{bB}$ & $26,67 \mathrm{cC}$ & 11,74 \\
\hline & $6 \mu \mathrm{M}$ AIB & $33,33 \mathrm{cA}$ & $33,33 \mathrm{dA}$ & $13,33 \mathrm{cB}$ & $6,67 \mathrm{~dB}$ & 20,03 \\
\hline & $\mathrm{CV} \%$ & 10,65 & 6,39 & 23,72 & 12,09 & \\
\hline \multirow{6}{*}{ 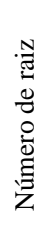 } & Concentração & 5 & 10 & 15 & 30 & $\mathrm{CV} \%$ \\
\hline & $0 \mu \mathrm{M}$ AIB & $1,08 \mathrm{aA}$ & $1,08 \mathrm{bA}$ & $1,08 \mathrm{aA}$ & $1,08 \mathrm{aA}$ & 0,00 \\
\hline & $1 \mu \mathrm{M}$ AIB & $1,00 \mathrm{aB}$ & $1,75 \mathrm{aA}$ & $1,00 \mathrm{aB}$ & $1,00 \mathrm{aB}$ & 10,53 \\
\hline & $2 \mu \mathrm{M}$ AIB & $1,11 \mathrm{aA}$ & $0,67 \mathrm{bA}$ & $1,33 \mathrm{aA}$ & $1,11 \mathrm{aA}$ & 15,02 \\
\hline & $4 \mu \mathrm{M}$ AIB & $0,67 \mathrm{aA}$ & $1,00 \mathrm{bA}$ & $1,00 \mathrm{aA}$ & $0,78 \mathrm{aA}$ & 19,76 \\
\hline & $6 \mu \mathrm{M}$ AIB & $1,00 \mathrm{aA}$ & $1,00 \mathrm{bA}$ & $0,67 \mathrm{aA}$ & $0,33 \mathrm{aA}$ & 19,29 \\
\hline \multirow{8}{*}{ 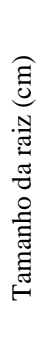 } & $\mathrm{CV} \%$ & 27,00 & 25,93 & 36,21 & 48,19 & \\
\hline & Concentração & 5 & 10 & 15 & 30 & $\mathrm{CV} \%$ \\
\hline & $0 \mu \mathrm{M}$ AIB & $0,21 \mathrm{aA}$ & $0,21 \mathrm{aA}$ & $0,21 \mathrm{aA}$ & $0,21 \mathrm{aA}$ & 0,00 \\
\hline & $1 \mu \mathrm{M}$ AIB & $0,19 \mathrm{aB}$ & $0,30 \mathrm{aA}$ & $0,10 \mathrm{bB}$ & $0,15 \mathrm{aB}$ & 23,04 \\
\hline & $2 \mu \mathrm{M}$ AIB & $0,17 \mathrm{aA}$ & $0,22 \mathrm{aA}$ & $0,22 \mathrm{aA}$ & $0,23 \mathrm{aA}$ & 7,12 \\
\hline & $4 \mu \mathrm{M}$ AIB & $0,15 \mathrm{aA}$ & $0,15 \mathrm{aA}$ & $0,12 \mathrm{bA}$ & $0,12 \mathrm{bA}$ & 6,87 \\
\hline & $6 \mu \mathrm{M}$ AIB & $0,17 \mathrm{aA}$ & $0,11 \mathrm{aA}$ & $0,10 \mathrm{bA}$ & $0,03 \mathrm{cA}$ & 5,02 \\
\hline & $\mathrm{CV} \%$ & 33,64 & 47,21 & 32,91 & 37,49 & \\
\hline
\end{tabular}

Médias seguidas da mesma letra minúscula na coluna e maiúscula na linha não diferem entre si a 5\% de probabilidade pelo teste Scott Knott. 
por SOUZA et al. (2011) com a espécie Dioscorea multiflora. De modo geral, as espécies arbóreas apresentam maior dificuldade de enraizarem in vitro do que espécies herbáceas, entretanto, plantas do Cerrado que possuem xilopódio, independente do habito de crescimento, apresentam dificuldade na indução e crescimento de raízes in vitro e uma alternativa para amenizar o problema é a aclimatização das plântulas logo após o processo de indução do enraizamento.

\section{Aclimatização}

A aclimatização das brotações de $\boldsymbol{C}$. antisyphiliticus apresentou índice de sobrevivência de 63,34\% (Figura 1C). O sucesso da aclimatização pode ser atribuído à associação dos seguintes fatores: uso de solo autoclavado, controle de temperatura e umidade. Esses fatores certamente facilitaram a passagem da condição heterotrófica (in vitro) para autotrófica (ex vitro).

Muitos autores têm afirmado que o sucesso da fase de aclimatização está diretamente relacionada a plântulas que apresentam raízes bem desenvolvidas in vitro (ANDRADE et al., 2000; GONÇALVES et al, 2010). No entanto, mesmo sem a presença de raízes nos propágulos de $\boldsymbol{C}$. antisyphiliticus, a porcentagem de sobrevivência ao processo de aclimatização foi considerada satisfatória.

\section{CONCLUSÃO}

A micropropagação de Croton antisyphiliticus pode ser realizada com explante gema apical inoculado em meio de cultura MS suplementado, com 1,0 $\mu \mathrm{M}$ de BAP, co-cultivadas em frascos tipo pote. $\mathrm{O}$ enraizamento in vitro ocorre sem a adição de regulador vegetal ao meio de cultura e a aclimatização das brotações é eficiente com ou sem a presença de raízes desenvolvidas in vitro.

\section{AGRADECIMENTOS}

À Coordenação de Aperfeiçoamento de Pessoal de Nível Superior (CAPES) e à Universidade de Ribeirão Preto (UNAERP).

\section{REFERÊNCIAS}

ANDRADE, M.W. et al. Micropropagação de aroeira (Myracrodruon urundeuva Fr.All). Ciência e Agrotecnologia, v.24, n.1, p.174180, 2000. Disponível em: <http://www.editora.ufla.br/site/_adm/ upload/revista/24-1-2000_21.pdf>. Acesso em: 15 jan. 2011.

AÑEZ, L.M.M. et al. Caracterização morfológica de frutos, das sementes e do desenvolvimento de plântulas de Jatropha elliptica Müll.Arg. (Euphorbiaceae). Revista Brasileira de Botânica, v.28, n.3, p.563-568, 2005. Disponível em:<http:/ /www.scielo.br/pdf/rbb/v28n3/29005.pdf>. Acesso em: 22 jan. 2011. doi: 10.1590/S0100-84042005000300012.

BARROS, M.A. Flora medicinal do Distrito Federal. Brasil Florestal, v.50, p.35-45, 1982.

BASKIN, C.C.; BASKIN, J.M. Seeds: ecology, biogeography and evolution of dormancy and germination. San Diego, CA: Academic, 1998. 498p.

CONCEIÇÃO, C.C.C. et al. Enraizamento de estacas de sacaca. Horticultura Brasileira, v.2, n.1, p.370-370, 2004. Disponível em: <http://www.abhorticultura.com.br/biblioteca/arquivos/ Download/Biblioteca/44_141.pdf>. Acesso em: 15 jan. 2011.

FERREIRA, B.G.A. et al. Miniestaquia de Sapium glandulatum (Vell.) Pax com o uso de ácido indol butírico e ácido naftaleno acético. Ciência Florestal, v.20, n.1, p.19-31, 2010. Disponível em: <http://www.ufsm.br/cienciaflorestal/artigos/ v20n1/A2V20N1.pdf $>$. Acesso em: 15 jan. 2011.

FERREIRA, D.F. SISVAR 5.1 - Análises estatísticas por meio do Sisvar para Windows. Lavras: Universidade Federal de Lavras, 2005. Disponível em: <http://www.dex.ufla.br/ danielff/ softwares.htm>. Acesso em: 10 maio, 2009.

GONÇALVES, S. et al. High-frequency in vitro propagation of the endangered species Tuberaria major. Plant Cell Tissue and Organ Culture, v.101, n.3, p.359-363, 2010. Disponível em: <http://www.springerlink.com/content/ v6745078t8857315/>. Acesso em: 10 abr. 2011. doi: 10.1007/ s11240-010-9683-y.

MARTINS, L.C. et al. Micropropagação e conservação de Macrosyphonia velame (St. Hil.) Muell. Arg. em banco de germoplasma in vitro. Ciência Rural, v.41, n.3, p.454-458, 2011. Disponível em: <http://www.scielo.br/pdf/cr/v41n3/ a903cr4191.pdf $>$. Acesso em: 10 abr. 2011. doi: 10.1590/ S0103-84782011005000015.

MENDES, R.C. et al. Tratamentos pré-germinativos em sementes de mamona (Ricinus communis L.). Revista Brasileira de Sementes, v.31, n.1, p.187-194, 2009. Disponível em: <http:/ /www.scielo.br/pdf/rbs/v31n1/a21v31n1.pdf >. Acesso em: 15 jan. 2011. doi: 10.1590/S0101-31222009000100021.

MURASHIGE, T.; SKOOG, F. A revised medium for rapid growth and bioassays with tobacco tissue cultures. Physiologia Plantarum, v.15, n.3, p.473-497, 1962. Disponível em: <http://dx.doi.org/10.1111/j.13993054.1962.tb08052.>. Acesso em: 5 fev. 2010. doi: 10.1111/ j.1399-3054.1962.tb08052.

NICOLOSO, F.T.; ERIG, A.C. Efeito do tipo de segmento nodal e tamanho do recipiente no crescimento de plantas de Pfaffia glomerata in vitro. Ciência e Agrotecnologia, Edição especial, p.1499-1506, 2002. Disponível em: <http:// www.editora.ufla.br/site/_adm/upload/revista/26-E2002_17.pdf>. Acesso em: 15 jan. 2011.

PEREIRA, A.M.S. et al. The effect on in vitro co-cultivation of Cephaelis ipecacuanha, Eclipta alba and Oryza sativa on plant development and yield of emetine, wedeloctane and demethyledelolactona. Acta Horticulturae, n.502, p.307- 
311, 1999. Disponível em: <http://www.actahort.org/books/ 502/502_50.htm>. Acesso em: 15 jan. 2011.

SAINT-HILARIE, A. Plantas usuais dos brasileiros. In: PIGNAL, M.; BRANDÃO. M.G.L. (Org.). Belo Horizonte: IDM Composição e arte, 2009. p.329-333.

SANTOS, R.B. et al. Micropropagação de pequizeiro (Caryocar brasiliense Camb.). Revista Brasileira de Fruticultura, v.8, n.2, p.293-296, 2006. Disponível em: <http://www.scielo.br/ pdf/rbf/v28n2/a31v28n2.pdf>. Acesso em: 22 jan. 2011. doi: 10.1590/S0100-2945200600020003.

SHIBATA, W. et al. Micropropagation of Croton sublyratus Kurz - a tropical tree of medicinal importance. Plant Cell
Report, v.16, p.147-152, 1996. Disponível em: <http:// dx.doi.org/10.1007/BF01890856>. Acesso em: 05 mar. 2011. doi: $10.1007 / \mathrm{BF} 01890856$.

SOUZA, A.V. et al. Micropropagação de Dioscorea multiflora Grised. Ciência e Agrotecnologia, v.35, n.1, p.92-98, 2011. Disponível em: <http://www.scielo.br/pdf/cagro/v35n1/ a11v35n1.pdf>. Acesso em: 05 mar. 2011. doi: 10.1590/ S1413-70542011000100011.

SUNGKUMLONG; DEB, C.R. Regeneration competence of Tainia latifolia (Lindl.) Benth ex Hook pseudobulb segments: an in vitro study. Indian Journal of biotechnology, v.8, n.1, p.121-126, 2009. Disponível em: <http://nopr.niscair.res.in/ bitstream/123456789/2947/1/IJBT\%208\%281\%29\%20121126.pdf>. Acesso em: 15 jan. 2011. 